ORIGINAL ARTICLE

\title{
Disease progression and adverse events in patients listed for elective percutaneous coronary intervention
}

\author{
S Talwar, M Karpha, R Thomas, C Vurwerk, I C Cox, C J Burrell, J G Motwani, T J Gilbert, \\ G A Haywood
}

Postgrad Med J 2005;81:459-462. doi: 10.1136/pgmi.2004.031344

\begin{abstract}
See end of article for authors' affiliations

Correspondence to:

Dr G A Haywood, South

West Cardiothoracic

Centre, Derriford Hospital,

Plymouth, PL6 8DH, UK;

guy.haywood@phnt.swest. nhs.uk
\end{abstract}

Submitted 25October 2004 Accepted

4 November 2004
Objective: To record disease progression and the timing of adverse events in patients on a waiting list for elective percutaneous coronary intervention (PCI).

Design: Observational prospective study.

Settings: A UK tertiary cardiothoracic centre, at a time when waiting lists for $\mathrm{PCl}$ were up to 18 months. Patients: 145 patients ( 116 men, median age 59.5 years) placed on an elective waiting list for $\mathrm{PCl}$ between October 1998 and September 1999.

Main outcome measures: Adverse events recorded were death, myocardial infarction, need for urgent hospital admission because of unstable angina, and need for emergency revascularisation while waiting for $\mathrm{PCl}$.

Results: During a median follow up of 10 months (range 1-18 months), nine (6.2\%) patients experienced an adverse event. Eight (5.52\%) patients were admitted with unstable angina as emergencies. One was admitted with a myocardial infarction. Twenty nine $(20.0 \%)$ patients had significant disease progression at the time of the repeat angiogram before $\mathrm{PCl}$. In $10(7 \%)$, disease had progressed so that $\mathrm{PCl}$ was no longer feasible and patients were referred for coronary artery bypass graft. Sixteen (1 1\%) were removed from the $\mathrm{PCl}$ waiting list because of almost complete resolution of their anginal symptoms.

Conclusion: Adverse coronary events and clinically significant disease progression occur commonly in patients waiting for $\mathrm{PCl}$. Despite the presence of severe coronary lesions, myocardial infarction was rare and no patients died while on the waiting list. Resolution of anginal symptoms was also comparatively common. The pathophysiology of disease progression frequently necessitates a change in the treatment of patients waiting for $\mathrm{PCl}$.
$\mathrm{T}$ he most important indication for elective percutaneous coronary intervention (PCI) is chest pain adversely affecting quality of life despite optimal medical treatment. There is some information on adverse event (AE) rates in patients waiting for elective PCI for up to a mean follow up of 24 months in the pre-secondary prevention/statin era. ${ }^{1}$ Some data are also available from trials where patients were randomised to medical treatment or PCI. ${ }^{2}$ However, with advances in PCI techniques more complex lesions and multivessel disease patients are being listed for elective PCI. In the past a higher proportion of such patients were treated with coronary artery bypass grafting (CABG) (Regional Audit Data 1997-2003 South West Cardiothoracic Centre, Plymouth, UK, unpublished data). Waiting times are of particular concern in these patients because adverse cardiac events and excess deaths have been reported on waiting lists for revascularisation by $\mathrm{CABG} .^{3-7}$

It is also important when advising patients on the risks and benefits of PCI to know the natural history in the medium term of treating such patients with medical therapy only. The chances of symptoms resolving on medical treatment over the following year, compared with the risks of a delay in PCI resulting in the need for $\mathrm{CABG}$ because of disease progression are of key importance.

This study aimed to assess the incidence and time points of adverse events in a representative cohort of patients from a UK elective PCI waiting list where the relative frequency of elective revascularisation by PCI compared with CABG is about 4:1 (Regional Audit Data 1997-2003 South West Cardiothoracic Centre, Plymouth, UK, unpublished data). Because of local factors operating in the south west of England in 1998-2000, the time these patients spent on the waiting list in the secondary prevention/statin era was longer than has been reported previously in the literature.

\section{METHODS}

The study group comprised 145 consecutive patients placed on the combined waiting list for elective PCI at the cardiothoracic centre in Plymouth, UK between 1 October 1998 and 30 September 2000. Patients were studied prospectively.

Demographic details, vessel distributions, severity of disease, and drug therapy at the time of listing for PCI were recorded. All patients were followed up from their initial presentation to the time of their PCI.

AEs recorded were: death, myocardial infarction (MI), the need for urgent or emergency hospital admission because of unstable angina (UA), and the need for ischaemia driven revascularisation because of significant angiographic disease progression related to the target lesion while on the waiting list. The time from the date patients were placed on the waiting list to the time AEs occurred was also recorded.

All statistical analysis was done using MINITAB (USA). Data are expressed as medians (ranges) or percentages, where appropriate. Pearson's correlation and logistic regression were performed. Significance was defined as $\mathrm{p}<0.05$.

\section{RESULTS}

The observational cohort was composed of 145 outpatients (116 men, median age 59.5 years (range 31-79 years)). Tables 1 and 2 summarise demographic details and vessel

Abbreviations: $A E$, adverse event; $\mathrm{Ml}$, myocardial infarction; $\mathrm{PCl}$, percutaneous coronary intervention; $C A B G$, coronary artery bypass graft; UA, unstable angina 
Table 1 Demographic data of the patient cohort

\begin{tabular}{ll}
\hline Total number of patients & 145 \\
Age (median (range) years) & $59.5(31-79)$ \\
Male (\%) & 79.6 \\
Smoker/former smoker (\%) & 65.3 \\
History of angina (\%) & 95.2 \\
History of myocardial infarction (\%) & 38.7 \\
History of hypertension (\%) & 25.2 \\
History of diabetes mellitus (\%) & 9.5 \\
History of peripheral vascular disease (\%) & 6.1 \\
History of stroke (\%) & 4.1 \\
Family history of coronary disease (\%) & 30.6 \\
Past history of PCI (\%) & 10.2 \\
Past history of CABG (\%) & 6.1 \\
Exercise tolerance test performed (\%) & 63.9 \\
Exercise tolerance test positive (\%) & 46.9 \\
Myocardial perfusion scans performed (\%) & 8.2 \\
Creatinine (median (range) $\mu$ mol/l) & $100(65-1047)$ \\
Cholesterol (median (range) mmol/l) & $5(4-8)$ \\
Number of vessels diseased (mean (range)) & $1.45(1-3)$ \\
Waiting time for PCI (median (range) months) & $10(1-18)$ \\
\hline
\end{tabular}

distributions of disease at the time of listing for PCI. Ninety per cent of the study population were treated with aspirin or an alternative antiplatelet agent, $67 \%$ received a $\beta$ blocker, $53 \%$ received a calcium channel antagonist, and $69 \%$ received a statin. Some $4.6 \%$ of the patients were not taking any antianginal drugs, while $68.2 \%$ took one to two antianginals and $27.2 \%$ took three to four antianginals.

During a median follow up of 10 months (range 118 months), nine (6.2\%) patients experienced an AE. One patient $(0.7 \%)$ was admitted with an MI and eight $(5.5 \%)$ were admitted with UA as emergencies, of which five (3.5\%) patients underwent emergency PCI. Six of these patients had progression of the target lesion and the remainder had angiographic evidence of new disease. The events are all summarised in table 3 . The median time from referral date to unplanned hospital admission was 11 months (range 3-16).

Of the study population, $29(20.0 \%)$ patients had angiographic progression of coronary disease at the time of their check angiogram before PCI. Of these patients, 14 (9.7\% of the total cohort) had progression of their target lesion to the extent of total or subtotal occlusion. Fifteen $(51.7 \%)$ patients, had disease progression to cause a new significant flow limiting stenosis separate to the target lesion. Of the 29 patients who had disease progression, only eight were admitted with UA/MI while on the waiting list, three had increasing anginal symptoms, one of which had to be transferred to the priority list. Two patients developed a sub-acute occlusion requiring rotablation and 10 were referred for CABG.

In $16(11.0 \%)$ patients, anginal symptoms significantly improved while waiting for PCI. Their names were removed from the PCI waiting list. A further three $(2.1 \%)$ had developed angiographic regression of their coronary disease at the time of the repeat angiogram and did not require PCI.

There was a positive correlation between the frequency of adverse events and the number of vessels diseased ( $r=0.16$, $\mathrm{p}=0.057)$. On stepwise logistical analysis in the whole population, history of a MI $(p=0.03)$ and left ventricular function $(\mathrm{p}=0.003)$ were independently associated with an $\mathrm{AE}\left(R^{2}=7.3 \%, \mathrm{p}<0.05\right)$.

\section{DISCUSSION}

As would be anticipated, the data show that waiting for elective PCI is not without risk. However, given the severity of the angiographic disease in the patients studied, the most striking feature is the absence of death and the rarity of MI $(0.7 \%)$. The most frequent clinical risk was emergency
Table 2 Coronary anatomy (\%) of angiographic disease in the study population

\begin{tabular}{lc}
\hline Left main stem & 0.68 \\
Proximal LAD & 19.2 \\
1 Vessel disease-proximal LAD & 50.7 \\
2/3 Vessel disease-proximal LAD & 20.5 \\
2/3 Vessel disease + proximal LAD & 8.9 \\
\hline
\end{tabular}

unplanned admission with a suspected acute coronary syndrome, but none of these admissions progressed to death or Q wave MI.

In contrast with the low risk of progression to a severe clinical event, $20 \%$ had significant angiographic disease progression while waiting. This correlates well with previous data. ${ }^{8-11}$ The highest risk group was patients with a previous MI or impaired left ventricular function. Events in these patients accounted for $69 \%$ of all events that occurred during the study. Absence of these two features therefore had a high negative predictive value of $80 \%$ for the prediction of AEs. The positive predictive value of these features was low at $20 \%$. Both history of MI and left ventricular function were independently associated with AEs, although the $R^{2}$ was only $7.3 \%$. Therefore, although clinically significant it will not prove to be useful clinically because it only accounts for $7.3 \%$ of the variance in the model. Our data therefore fail to provide a means to identify which patients are likely to go on to experience an AE while waiting for PCI.

Of the patients who had coronary disease progression, very few of them had worsening symptoms or required hospitalisation. Stable symptoms, where commonly associated with "silent" disease progression, even to the extent of total occlusion, making PCI less effective and more challenging. ${ }^{12}$ Despite evidence of disease progression there was little change in the severity of target lesions between angiograms. This finding is consistent with previous studies and emphasises the fact that the stenosis in the intended target lesion is not necessarily the lesion most at risk for progression. $^{13}$

In total, 16 patients (11\%) had improvement of their symptoms while on the waiting list and were thus removed, and three patients had angiographic evidence of disease regression at repeat angiography on admission. This comparatively frequent improvement in patients clinical status shows that patients who go onto PCI waiting lists should be reassessed before admission and informed at the time they are placed on the waiting list that there is a chance their symptoms may resolve and that elective PCI may cease to be indicated.

Hospitalisation while on the waiting list occurred during a period of 92 to 488 days. Although this may show that waiting lists of less than three months may be associated with low rates of progression to emergency hospital admission, it is not possible to comment on a "safety period" for being on the waiting list, as silent progression of coronary lesions to untreatable occlusions may have occurred early without being indicated by clinical signs. Patient 9 in table 3 was admitted to hospital as an emergency after being on the waiting list for 339 days. The repeat angiogram showed progression of the initial RCA target lesion to total occlusion, not amenable to angioplasty. However, there was new significant disease in the left anterior descending artery (LAD) and had this patient received angioplasty after waiting a short period of time on the waiting list, it is quite possible that they still would have been admitted as an emergency because of the progression of separate disease in the LAD.

Opinion in the USA has suggested that patients should not wait any longer than one to two weeks after a cardiac event 
Table 3 Major adverse events while on waiting list

\begin{tabular}{|c|c|c|c|c|c|c|c|c|}
\hline $\begin{array}{l}\text { Patient } \\
\text { number }\end{array}$ & Age & Sex & Diabetic & Previous MI & LV Fx & Clinical end point & Procedure & $\begin{array}{l}\text { Time on waiting } \\
\text { list to clinical event } \\
\text { (days) }\end{array}$ \\
\hline 1 & 74 & $M$ & No & Yes, CABG & Mild impairment & MI on waiting list. & $\mathrm{PCl}$ to $\mathrm{Cx}$ and $\mathrm{RCA}$ & 396 \\
\hline 2 & 58 & $\mathrm{~F}$ & No & No & Good & UA on waiting list & $\mathrm{PCl}$ to $\mathrm{Cx}$ and $\mathrm{RCA}$ & 92 \\
\hline 3 & 59 & $\mathrm{~F}$ & No & Yes & Good & UA on waiting list & $\mathrm{PCl}$ to $\mathrm{RCA}$ & 488 \\
\hline 4 & 73 & $M$ & No & Yes & Mild impairment & UA on waiting list & $\mathrm{PCl}$ to $\mathrm{D} 2$ & 177 \\
\hline 5 & 59 & $M$ & No & Yes & Mild impairment & UA on waiting list & $\mathrm{PCl}$ to RCA and LAD & 147 \\
\hline 6 & 69 & $M$ & No & No & Good & UA on waiting list & $\mathrm{PCl}$ to RCA and LAD & 479 \\
\hline 7 & 73 & M & No & Yes & Good & UA on waiting list & $\mathrm{PCl}$ to $\mathrm{LAD}$ and $\mathrm{DI}$ & 177 \\
\hline 8 & 48 & $M$ & No & No & Good & UA on waiting list & * & 135 \\
\hline 9 & 78 & $\mathrm{~F}$ & No & Yes & Mild impairment & UA on waiting list & $\dagger$ & 339 \\
\hline \multicolumn{9}{|c|}{ 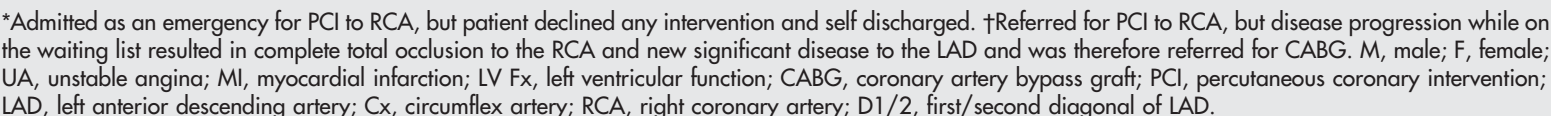 } \\
\hline
\end{tabular}

before undergoing PCI. ${ }^{14}$ In the population reported by these authors there was a high rate of early acute MI. However, our data differ from these findings. This may be because of a longer time period between onset of presenting symptoms such as chest pain and patients undergoing coronary angiography in the UK. This may result in most patients on UK waiting lists being in a more chronic phase of clinically apparent coronary disease. National service framework guidelines on waiting times for PCI suggest that patients should not have to wait longer than six months at present, with an aim to improve the waiting time to three months by 2005. ${ }^{15}$ Ideally the time interval between coronary angiography and elective PCI should be no longer than is required for the patient, patient's family, and physician to have what ever time they feel is required for gaining adequate informed consent for the revascularisation procedure. This would reduce the comparatively high frequency of adverse events that we observed to a minimum. It is, however, somewhat

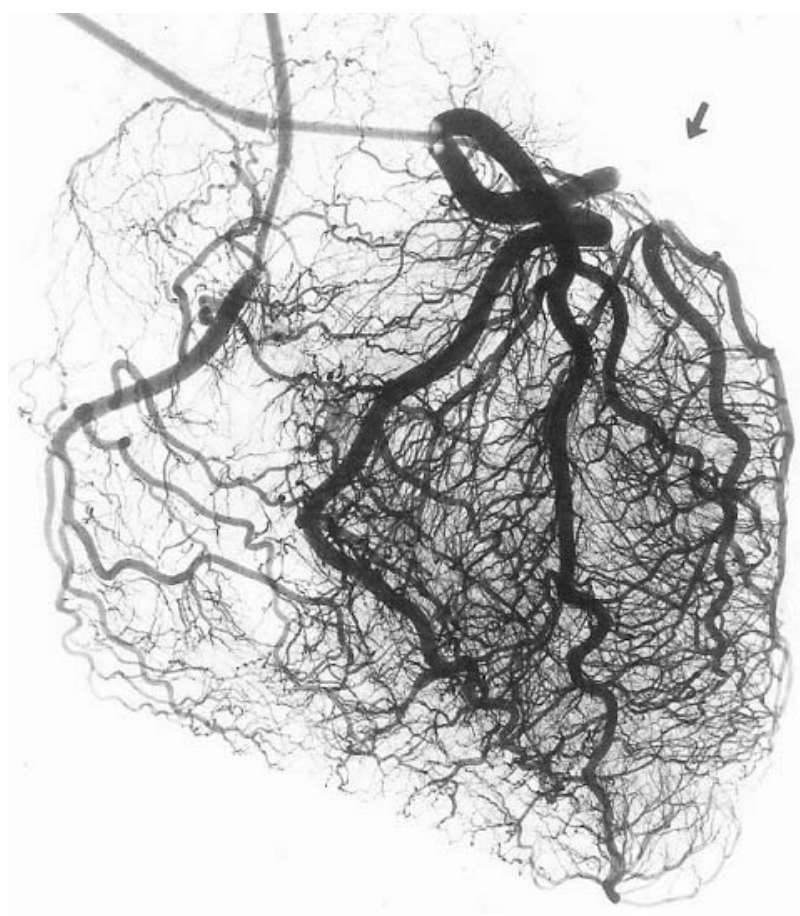

Figure 1 Filling of coronary collaterals in a normal postmortem human heart by immersion radiography. The arrow shows ligation of a proximal branch of the cirumflex with back filling of the distal vessel by collaterals. Reproduced with permission (Fulton WFM. Immersion radiography of injected specimens. Br J Radiol 1963;36:687). reassuring that despite the excessively long waiting times in our study, there was a complete absence of death or major MI.

\section{Pathogenesis}

Adverse cardiac events are attributed to the process of coronary artery disease progression over time. ${ }^{16}$ Risk factors and disease severity contribute to disease progression. However, progression of coronary disease is a non-linear process and follows an unpredictable course over several years. ${ }^{17-22}$ The process can lead to total occlusion of a vessel or new stenoses developing in areas of the coronary circulation that were found to be normal at previous investigation. ${ }^{23}$ Furthermore, rapid stenosis progression occurring over shorter periods of time is thought to be the process underlying acute coronary syndrome. ${ }^{24}$ Large plaques are at a higher risk of rupture than small plaques. Nevertheless, it has been hypothesised that the risk of a MI arising from a small plaque is greater overall, as small plaques are far more

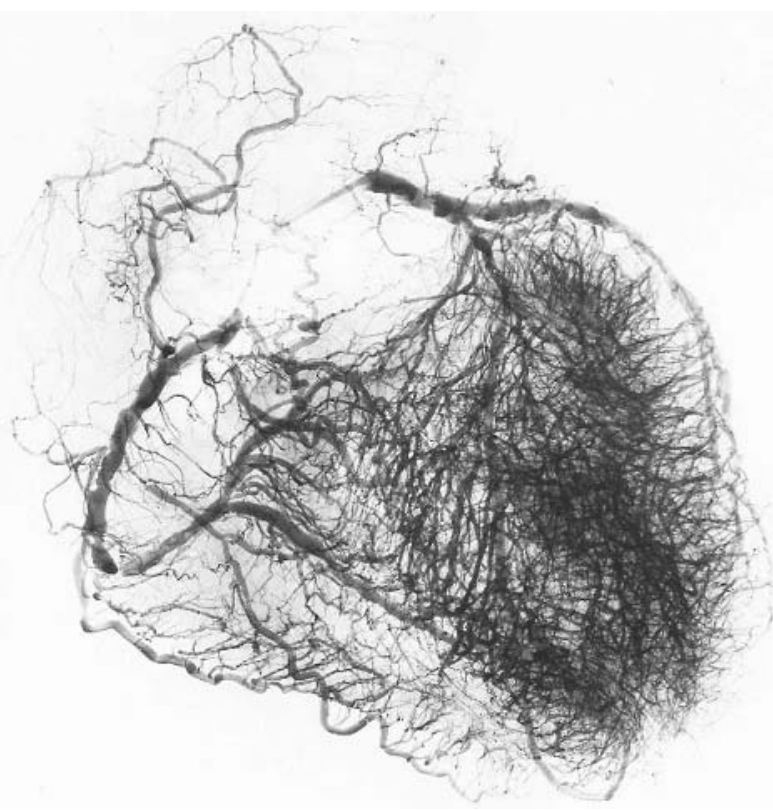

Figure 2 Filling of coronary collaterals in a postmortem human heart by immersion radiography. Extensive enlargement and recruitment of small calibre collaterals in a patient with chronic coronary artery disease. Reproduced with permission from Georg Theine, Stuttgart. (Fulton WFM. Intercoronary anastamoses studied by post-mortem stereoarteriography. In: Kattenbach JP, et al, eds. Coronary heart disease 1978). 
common than large plaques. ${ }^{25}$ The absence of symptomatic deterioration despite vessel occlusion may well be dependent on the development of coronary collaterals, which have been shown to develop over a time course of 6-12 months in humans (see figs 1 and 2). ${ }^{26}$

The neovascularisation process occurs by growth from both the adventitia and the arterial lumen and extends into the intima of advanced plaques. The intra-plaque neovasculature is fragile and has an increased susceptibility to rupture. When the process of plaque rupture and healing occurs repeatedly, there is a layering effect of the plaque, which may account for the intermittent step-wise pattern of growth in the plaque. ${ }^{25}$

\section{Limitations}

The study has its limitations. Firstly, it does not measure mortality or morbidity in patients earlier in the care pathway, for instance, when they were waiting for coronary angiography. This is an important phase in the natural history of coronary disease in these patients as many had waited for several months for coronary angiography. Secondly, the low number of women in this study as in other reports has prevented assessment of potentially important sex differences with regards to AEs. Thirdly, as death and MI are clearly infrequent events in this population, a larger study would be required to give an accurate assessment of the small number of patients at risk for these most serious adverse events.

\section{CONCLUSION}

The benefits of PCI in reducing symptoms and improving quality of life are established. A long waiting time before receiving definitive treatment not only leaves patients suffering from symptoms that significantly impair quality of life, but in some may also result in a reduced probability of overall benefit from PCI because of silent disease progression. Fortunately, death and major cardiac damage from MI seem to be uncommon. The complexity of the pathogenetic processes underlying coronary artery disease result in a wide range of changes that occur in stable angina patients over a 10 month median period and, in this series, resulted in PCI no longer being the most appropriate treatment in $18 \%$.

These findings provide the most extended study of the natural history of patients with chronic stable angina in the secondary prevention/statin era listed for PCI.

\section{Authors' affiliations}

S Talwar, M Karpha, R Thomas, C Vurwerk, I C Cox, C J Burrell, J G Motwani, T J Gilbert, G A Haywood, South West Cardiothoracic Centre, Derriford Hospital, Plymouth, UK

Funding: none.

Conflicts of interest: none declared.

\section{REFERENCES}

1 Chester M, Chen L, Kaski JC. Identification of patients at high risk for adverse coronary events while awaiting routine coronary angioplasty. Br Heart J 1995;73:216-22.
2 Bucher HC, Hengstler $\mathrm{P}$, Schindler $\mathrm{C}$, et al. Percutaneous transluminal coronary angioplasty versus medical treatment for non-acute coronary heart disease: meta-analysis of randomised controlled trials. BMJ 2000;321:73-7.

3 Naylor CD, Sykora K, Jaglal SB, et al. Waiting for CABG: population based study of 8517 consecutive patients in Ontario, Canada. Lancet 1995;346:1605-9.

4 Silber S, Muhling H, Dorr R, et al. Waiting times and death on the waiting list for CABG operations: experience in Munich with over 1000 patients. (In German.) Herz, 1996:21:389-96.

5 Bengston A, Karlsson T, Hialmarson A, et al. Complications prior to revascularisation among patients waiting for CABG and PTCA. Eur Heart $J$ 1996;17:1846-51.

6 Morgan CD, Sykora K, Naylor CD, for the steering committee of the Cardiac Care Network of Ontario. Analysis of deaths while waiting for cardiac surgery among 29,293 consecutive patients in Ontario, Canada. Heart 1998;79:345-9.

7 Suttorp MJ, Kingma JH, Vos J, et al. Determinants for early mortality in patients awaiting $C A B G$ : a case control study. Eur Heart J 1992; 13:238-42

8 Moise A, Theroux P, Taeymans $Y$, et al. Clinical and angiographic factors associated with progression of coronary artery disease. J Am Coll Cardiol 1984;3:659-67.

9 Moise A, Lesperance J, Theroux $\mathrm{P}$, et al. Clinical and angiographic predictors of new total coronary occlusion in coronary artery disease: analysis of 313 nonoperated patients. Am J Cardiol 1984;54:1 176-81.

10 Brown B, Zhao XQ, Sacco DE, et al. Lipid lowering and plaque regression: new insights into prevention of plaque disruption and clinical events in coronary disease. Circulation 1993;87:1781-91.

11 Taeymans Y, Theroux P, Lesperance J, et al. Quantitative angiographic morphology of the coronary artery lesions at risk of thrombotic occlusion. Circulation 1992;85:78-85.

12 De Feyter PY, Serruys PW. PTCA for unstable angina. In: Topol EJ, ed. Textbook of interventional cardiology. 2nd ed. Philadelphia: W B Saunders, 1994:274-91.

13 Kaski JC, Chen L, Chester M. Rapid angiographic progression of "target" and "nontarget" stenosis in patients awaiting coronary angioplasty. J Am Coll Cardiol 1995;26:416-21.

14 Rosanio S, Tocchi M, Cutler D, et al. Queuing for coronary angiography during severe supply-demand mismatch in a US public hospital: analysis of a waiting list registry. JAMA 1999;282:145-52.

15 Department of Health. National Service Framework for coronary heart disease. London: Department of Health, 2000.

16 Lichtlen P, Nikutta P, Jost S, et al. Anatomical progression of coronary artery disease in humans as seen by prospective, repeated, quantitated coronary angiography: relation to clinical events and risk factors. Circulation 1992;86:828-38.

17 Bemis CE, Gorlin R, Kemp HG, et al. Progression of coronary artery disease. A clinical arteriographic study. Circulation 1973;47:455-64.

18 Bruschke AV, Wijers TS, Kolsters W, et al. The anatomic evolution of coronary artery disease demonstrated by coronary arteriography in 256 non-operated patients. Circulation 1981;63:527-36.

19 Singh R. Progression of coronary atherosclerosis. Clues to pathogenesis from serial coronary arteriography. Br Heart J 1984;52:451-61.

20 Ambrose JA, Tannenbaum MA, Alexopoulos D, et al. Angiographic progression of coronary disease and the development of MI. J Am Coll Cardiol 1988; 12:56-62

21 Taeymans Y, Theroux P, Lesperance J, et al. Quantitative angiographic morphology of the coronary artery lesions at risk of thrombotic occlusion. Circulation 1992;85:78-85.

22 Kaski JK, Chester MR, Chen L, et al. Rapid angiographic progression of coronary artery disease in patients with angina pectoris. The role of complex stenosis morphology. Circulation 1995;92:2058-65.

23 Cox ID, Schwartzman RA, Atienza F, et al. Angiographic progression in patients with angina pectoris and normal or near normal coronary angiograms who are restudied due to unstable symptoms. Eur Heart $J$ 1998; 19:1027-33.

24 Moise A, Theroux P, Taeymans $Y$, et al. Unstable angina and progression of coronary atherosclerosis. N Engl J Med 1983;309:685-9.

25 Heistad DD. Unstable coronary artery plaques. N Engl J Med 2003;349:2285-8.

26 Fulton WFM. The time factor in the enlargement of anastomosis in coronary artery disease. Scott Med J 1964;9:18-23. 